\title{
A Criminalização das Identidades Trans na Escola: Efeitos e Resistências no Espaço Escolar
}

\section{The Criminalization of Transsexual Identities at School: Effects and Resistance in School Place}

\section{La Criminalización de las Identidades Trans en la Escuela: Efectos y Resistencias en el Espacio Escolar}

\author{
Flávio de Oliveira Natal-Neto
}

Discente de graduação em Psicologia da Universidade Federal do Rio de Janeiro.

Geovani da Silva Macedo

Discente de graduação em Psicologia da Universidade Federal do Rio de Janeiro.

\section{Pedro Paulo Gastalho Bicalho}

Professor Associado do Instituto de Psicologia do Programa de Pós-graduação em Psicologia e do Programa de Pós-graduação em Politicas Públicas em Direitos Humanos da Universidade Federal do Rio de Janeiro.

Resumo

O presente artigo, organizado na forma de um ensaio, discorre sobre a criminalização das identidades trans na escola, entrecortadas hegemonicamente pelas mais variadas dificuldades e violências, como efeitos a processos de repreensão que se operam articulados a normatizações de gênero e fazem operar subjetividades estigmatizadas. Tais processos, operados por lógicas de controle social que compulsoriamente delimitam comportamentos considerados como corretos e coerentes ao gênero a que se é atribuído à época do nascimento (ou, ainda, durante a gestação), fazem emergir aspectos da instituição escolar desconectados da garantia de direitos, da promoção de políticas públicas inclusivas e da promoção da equidade associada ao respeito às diferenças.

Palavras-chave: violência escolar; identidade de gênero; estigma; discriminação social; subjetividade.

Abstract

This essay addresses the criminalization of transexual identities in school, hegemonically constituted for a variety of difficulties and violences, as effect of reproof processes that operate articulated norms of gender that make subjectivities stigmatized. Such processes operated by the logic of social control that mandatorily delimit behaviors considered as correct and consistent to the gender to which is assigned at the time of birth (or even during pregnancy) bring out aspects of the school disconnected from the guarantee of rights, promoting inclusive public policies and promotion of equity associated with respect for differences.

Keywords: school violence; gender identity; stigma; social discrimination; subjectivity.

Resumen

El presente artículo, organizado en la forma de un ensayo, discurre sobre a criminalización de las identidades trans en la escuela, entrecortadas hegemónicamente por las más variadas dificultades y violencias, como efectos a procesos de reprensión que se operan articulados a normalizaciones de género y hacen operar subjetividades estigmatizadas. Tales procesos, operados por lógicas de control social que compulsoriamente delimitan comportamientos considerados como correctos y coherentes al género a que se es atribuido a la época del nacimiento (o, todavía, durante la gestación), hacen emerger aspectos de la institución escolar desconectados de la garantía de derechos, de la promoción de políticas públicas inclusivas y de promoción de la equidad asociada al respeto a las diferencias.

Palabras-clave: violencia escolar; identidad de género; estigma; discriminación social; subjetividad. 
A perspectiva de análise evidenciada no presente texto parte de duas premissas: a primeira, os processos de criminalização correspondem à constituição histórica e social de sistemas normativos, não necessariamente aliados à tipificação penal (Dornelles, 1988). Tais normatizações constituem-se a partir de postulados aliados a uma ideologia de defesa social (Baratta, 2013) e, ao serem transgredidos, produzem efeitos diversos, relativos a ações de punição. Os processos de criminalização indicam a constituição de critérios de definição de estigmas e periculosidade; portanto, indicam os caminhos dos efeitos de marginalização social, operados pela produção da subjetividade articulada à construção de políticas de medo (Cunha \& Bicalho, 2015). A segunda premissa é que partimos do fato de que as experiências de pessoas trans têm sofrido intensas investidas criminalizantes por se caracterizarem enquanto experiências identitárias desviantes à norma vigente de produção e estética dos corpos. Portanto, afirmamos tais experiências no plural por se tratar de multiplicidades. A experiência transexual no singular nos aponta um dos modos possíveis de incidência dos processos de criminalização, o que indica a homogeneização e simplificação de discursos, práticas e vivências que são singulares e complexos. As experiências trans sofrem efeitos dos processos de criminalização que incidem sobre seus corpos e experiências em diferentes sentidos: da inteligibilidade à execução em praça pública, promovendo efeitos severos a estas existências, não só na instituição escolar e em como o olhar dos representantes desta instituição coopera em gerar preconceito e estigmatização acerca de pessoas transexuais, mas também na sociedade e outras instituições como um todo. E, por outro lado, necessita-se pontuar: existem outros processos de criminalização operados pela instituição escolar. A experiência trans é o analisador que materializa a racionalidade presente na discussão deste artigo, mas poderiam ser outros exemplos, outras histórias, outros personagens. Racionalidades que se operam pela produção da subjetividade, fato que convoca o saber psicológico (que se constrói e faz operar intervenções) à escola.

Pessoas que expressam identidades de gênero fora da norma binária instituída têm dificuldades nas mais variadas esferas da vida cotidiana e pragmática, sendo os embaraços e violências perpassados os mais variados possíveis, como a dificuldade de inserção no mercado de trabalho formal. Na instituição escolar são comuns relatos de dificuldade de utilização do nome social nas folhas de frequência, do uso de uniforme adequado ao gênero (e não ao sexo biológico), bem como a utilização de sanitários (Cidade \& Bicalho, 2016).

Segundo dados da Associação Nacional de Travestis e Transexuais (ANTRA), devido ao preconceito e à dificuldade de se conseguir um emprego, $90 \%$ das travestis e transexuais trabalham na prostituição (Lapa, 2013). Seus diretos básicos são negados constantemente, como ter o nome social respeitado, o impedimento do uso do banheiro ou do vestuário correspondente ao seu gênero de identificação (Bento, 2011; Cruz, 2011).

Estes direitos podem ser retirados a partir de dispositivos do Estado, tal qual no momento em que o juiz recusa a mudança de documentos de uma pessoa transexual ou na dificuldade da concessão à adoção de uma criança pelo juiz, por exemplo. Esta criminalização da identidade trans ressoa no juiz, ser pertencente ao judiciário, que atravessado pelos processos de criminalização, considerará estas identidades como anormais e perniciosas à criança, tal qual no caso de Roberta Goés Luiz ${ }^{1}$, em que o juiz retirou a guarda de seu bebê de 11 meses (Siqueira, 2008).

É importante observar que o Brasil é o país que mais mata travestis e transexuais da América Latina: 325 assassinatos de 2008 a $2011^{2}$. Inclusive, é de fácil acesso vídeos que comprovam o ódio e a transfobia que a comunidade trans sofre, tal qual o assassinato de Laura Vermont (Brasilpost, 2015)

\footnotetext{
${ }^{1}$ http://www.conjur.com.br/2008-jan-10/mae_adotiva_perde_guarda_filho_transexual

${ }^{2}$ http://www.transrespecttransphobia.org/uploads/downloads/TMM/TvTTMMTables20082011en.pdf
} 
que fora filmada antes de executada ou de Idete, morta a facadas (Jesus, 2010). O aumento das mortes cresce de forma vertiginosa, nos fazendo refletir sobre as demandas em políticas públicas que visem combater a transfobia e o feminicídio do qual essas mulheres estão sendo vítimas (Silva \& Bicalho, 2014).

$\mathrm{O}$ artigo $3^{\circ}$ da Declaração Universal dos Direitos Humanos é claro em seu enunciado: “Todo indivíduo tem direito à vida, à liberdade e à segurança pessoal” (ONU, 1948). Contudo, sabe-se que nem todos os seres humanos têm seus direitos igualmente respeitados, como na situação das pessoas trans. Além dos direitos negados pelas instituições, ainda precisam lidar com violências de todos os tipos: física, simbólica, psicológica, sexual, dentre outras. São compreendidas como transexuais quaisquer pessoas que buscam reconhecimento social e legal para o gênero com o qual se identificam e são conceituadas como 'cisgêneros' as pessoas cuja identidade de gênero está de acordo com o seu sexo biológico (Jesus, 2010).

O artigo, portanto, irá tratar das questões da criminalização das identidades trans focalizado na instituição escolar, espaço ímpar de sociabilidade e de contato com o "outro" fora do meio familiar.

\section{A Criminalização da transexualidade}

Foucault (1976/1993) analisa como a construção das "verdades" oriundas das práticas de controle social, moral, do saber científico irão constituir práticas de repressão aos discursos e manifestações ditas como anormais e perniciosas ao bemestar social, constituindo criminalização das formas de ser e existir que divergem das hegemonicamente constituídas.

A criminalização trata, pois, de um processo desencadeado por infrações às leis sociais, presentes nos discursos socialmente estabelecidos e institucionalizados. O infrator de tais normas sofre represálias do meio, tendo sua existência negada e considerada como não eficiente e/ou incorreta. Ele exorta a imediata reforma das práticas ditas incorretas e amorais, quando não, legado aos infratores um lugar de subalterno e inferior (Bicalho, Geraldini, Magalhães, \& Cassal, 2012).

Os discursos criminalizantes do Ocidente irão alocar a existência das minorias à anormalidade e marginalidade, colocando o negro em local de potencial criminoso, a mulher ao histerismo e a posição de sexo frágil, subalterno ao homem e às divergências sexuais a um espaço pelo qual passam por vigília, análise e confissão diante do "poder" religioso e cristão.

A sexualidade passa a ser considerada uma face da natureza humana que deve ser confessada, vigiada e situada dentro da normalidade. Tais discursos sobre a sexualidade, reforçados pelo meio social e institucional, promovem a constante repressão do que foge à "verdade", instituindo comportamentos afixados de como se agir ao ser "mulher" e "homem", punindo variações à regra (Cassal, Monteiro, \& Bicalho, 2011).

Exemplificando através de Arán (2006):

Falar de sexualidade é também se referir à produção dos saberes que a constituem aos sistemas de poder que regulam suas práticas e às formas pelas quais os indivíduos podem e devem se reconhecer como sujeitos sexuados. Em outras palavras, sexo - homem, mulher - não é um simples fato ou uma condição estática, e sim "uma construção ideal forçosamente materializada através do tempo". (p. 51)

É indispensável observar que nada há de absoluto nos discursos que criarão objetos e subjetividades, das quais os saberes, sendo estes legislativos, científicos ou morais, irão se apoderar para moldá-los aos aspectos desejados de acordo com uma suposta salubridade social. Baptista (1999), em uma analogia dos discursos criminalizantes com a ação dos amoladores de facas, compreendidos como os discursos de repreensão as práticas ditas como anormais e erradas, deixando marcas e sofrimento aos que sofrem seu efeito: 
O que os amoladores de facas têm em comum é a presença camuflada do ato genocida. São genocidas, porque retiram da vida o sentindo de experimentação e de criação coletiva. Retiram do ato de viver o caráter pleno de luta política e o da afirmação de modos singulares de existir. São genocidas porque entendem a Ética como questão de polícia, do ressentimento e do medo. Não acreditam em modos de viver, porque professam o credo da vida como fardo ou dádiva. (p. 49)

É necessário questionar a construção destes discursos considerando sua origem e influência histórica construindo, a partir deste ponto, novas formas de existir que assegurem os direitos das pessoas transexuais. Porém, para tal é necessário compreender como têm sido construídos os olhares sobre a transexualidade junto às instituições, sendo seus preconceitos firmemente alicerçados no discurso de patologização da transexualidade decorrente do discurso médico, um discurso de saber poder que retira a autonomia e direito da pessoa transexual/travesti, delegando-a o status de doente necessitado de um laudo, saber e técnicas médicas para seu total restabelecimento.

\section{A patologilização das identidades trans}

As pessoas transexuais sofrem um controle especial sobre seus corpos a partir da noção da transexualidade como doença. De acordo com o 10a edição da Classificação Estatística Internacional de Doenças e Problemas Relacionados à Saúde (CID10), "transexualismo" é um "transtorno de identidade sexual” (OMS, 2010). Desde 1997, o Conselho Federal de Medicina permite a realização de cirurgias de transgenitalização no Brasil, desde que o paciente tenha o seguinte diagnóstico: o paciente transexual é portador de desvio psicológico permanente de identidade sexual, com rejeição do fenótipo e tendência à automutilação ou autoextermínio (Arán, Murta, \& Lionço, 2009).

Essa é uma leitura baseada em argumentos históricos produzidos sobre os corpos que hoje acabam sendo impostos como verdade ao serem naturalizados. Esse mesmo diagnóstico pode ser considerado um vetor de patologização e de estigma, pois atribui uma patologia ao sujeito (transformado em paciente) sem problematizar as questões históricas, políticas e subjetivas dessa psiquiatrização nosológica.

Nota-se que o que define o diagnóstico do dito transexualismo é uma concepção normativa dos sistemas de sexogênero, fundamentados numa matriz binária heterossexual que se converte em sistema regulador da sexualidade e da subjetividade (Arán, 2006). O sufixo "ismo", em transexualismo, remete a uma marcação de doença, a uma patologização dessas formas de ser, enquanto o termo transexualidade não se refere a práticas sexuais ou a sexualidade, mas às vivências identitárias de gênero (Jesus, 2010).

A partir da concepção de certas performances de gênero como doença, essas categorias que não cabem dentro do "ser homem" ou "ser mulher", produz-se "correções" para estas pessoas: cirurgias, terapias de adequação comportamental, medicações. Com isso, para validar a existência dessas identidades, não bastam apenas as falas e os desejos dos sujeitos. É necessário que vários discursos possam permitir essas existências, tornando-as válidas.

Sobre estas intervenções, Jesus (2010) aponta que se reconhece na legislação e nos procedimentos de saúde que eventualmente volta-se para as pessoas transexuais um profundo desrespeito à autopercepção e uma tentativa de domínio sobre suas identidades, por meio do controle sobre o direito ao reconhecimento legal de seu gênero e sobre o próprio processo de intervenção corporal, considerando a hormonioterapia e procedimentos plásticos ocasionalmente necessários, dependendo do indivíduo, tais como lipoaspiração, eletrólise ou depilação a laser, raspagem do pomodeadão e a própria cirurgia de transgenitalização, entre outros.

De acordo com Arán et al. (2009), o processo de assistência para a realização de cirurgia de redesignação sexual é constituído de avaliação e acompanhamento psiquiátrico periódico para confirmação do diagnóstico; psicoterapia individual e de grupo; hormonioterapia, 
com o objetivo de induzir o aparecimento de caracteres sexuais secundários compatíveis com a identificação psicossexual do paciente; avaliação genética; tratamento cirúrgico.

Porém, de acordo com Jesus (2010), mesmo quando as pessoas trans realizam modificações em seus corpos para adequá-los ao seu gênero, como a utilização de hormônios, alguns laudos psicológicos e médicos não conferem o "diagnóstico" transexual. São negados porque são consideradas mudanças menores que a cirurgia de redesignação. Ou seja, mesmo que a pessoa trans esteja satisfeita com seu corpo, ela precisa modificá-lo para ter o direito de viver sua identidade de forma livre e independente.

Tomemos, por exemplo, um pedido de mudança de documentos de uma pessoa trans na Justiça. Serão necessários laudos de psiquiatras, assistentes sociais, psicólogos, entrevistas com a família, entre outros discursos, para fazer valer o desejo desse indivíduo. $\mathrm{E}$ ainda assim, mesmo com o aval de todos eles, pode ter o seu pedido negado pelo juiz, sem contar dos procedimentos supracitados, considerados imprescindíveis por muitos juízes (Cidade \& Bicalho, 2016). A partir disso vale a pergunta: a genitália que possuímos define se somos homens ou mulheres?

Os discursos produzidos não são "inocentes", entretanto. Eles produzem profundas mudanças nas pessoas. Quando se diz que uma pessoa transexual sofre de incongruência acentuada entre o gênero experimentado/expresso e o gênero designado de uma pessoa, com duração de pelo menos seis meses (Cidade \& Bicalho, 2016), sabe-se que isto não é inócuo. Marca-se nesse indivíduo que, por estar "errado", ele precisa de ajuda. Não é de se estranhar, portanto, que ele procure "correção". E as marcas começam cedo: na família, entre os vizinhos, na escola.

Vale ressaltar que não basta ser apenas uma doença. Quando uma pessoa trans reporta-se aos "produtores de suas verdades", ou seja, médicos, assistentes sociais, psicólogos, é necessário mostrar uma condição de pessoa triste, que teve uma infância sofrida, demonstrar que odeia o seu corpo. Dessa forma, cria-se uma justificativa para permitir que esta pessoa possa assumir a sua própria identidade: a dor causada por essa inadequação. Essa dor é devida a processos de criminalização da transexualidade, que a irão situar como inadequada e doentia. Seria vital o papel da escola na construção de um ambiente que promovesse o acesso e garantia aos direitos das pessoas transexuais. Entretanto, este é outro ambiente de severa violência e desconforto.

\section{Transexualidade e Escola}

A escola é um espaço fundamental para a formação cidadã dos indivíduos. E como qualquer espaço social, é formado por pessoas, sendo estas atravessadas pelas mais diferentes ideias e processos. A escola, portanto, é um espaço que produz discursos sobre a sexualidade e sobre gênero e/ou reforça aqueles que são proferidos fora dos muros escolares, ainda que haja um "pacto silencioso", uma tentativa de evitar tocar no assunto: “(...) a escola muitas vezes não é vista como um lugar onde a sexualidade deva ser expressada ou discutida. Em seu aparente silêncio, na verdade, ela fala o tempo todo sobre sexualidade" (Bortolini et al., 2014, p.13).

Nas práticas mais variadas, como nos discursos do vestuário adequado, nas brincadeiras entendidas como corretas, nas formas de comportamento reprováveis pelos professores, já se percebe do quanto a idealização das práticas corretas e incorretas de acordo com o gênero se faz presente nas escolas. Para compreender o quanto a escola reitera os papéis de gênero, sendo um potente formador de "homens e mulheres":

Para citar exemplos mais modernos, a divisão por sexo nas aulas de Educação Física - e os esportes atribuídos a meninos ou meninas; as filas de meninos e de meninas na Educação Infantil; as distinções sexistas de vestuário - meninos não podem usar brincos nem cabelo comprido; a forma dos professores tratarem alunos homens ou mulheres, com rispidez ou com delicadeza; a tolerância da violência, verbal e até mesmo física, entre meninos; a preocupação constante com a manifestação da sensualidade das adolescentes (Bortolini et al., 2014, p. 13-14). 
Logo, com tantas distinções nas regras, maneiras de se comportar e espaços para ocupar, não é de se espantar que as crianças e os adolescentes internalizem as "regras do jogo" escolar e passem a punir os que não as cumprem: o menino efeminado, a menina "masculina", as pessoas transexuais.

É de se notar que a partir dos dados da pesquisa realizada pelo projeto Diversidade Sexual na Escola da Universidade Federal do Rio de Janeiro, em 2007 e 2008, Bortolini (2008) conclui que as questões de sexualidade e gênero, para os educadores, são como algo que precisa ser resolvido, discutido, encaminhado, enfim, algo que, se não constitui um problema declaradamente, coloca-se como uma questão com a qual é preciso lidar e diante da qual precisamos agir.

Com isso, nota-se mais uma vez que os discursos proferidos não são inertes. Eles causam efeitos nos alunos e alunas transexuais. Como ficar num espaço onde não é respeitada a própria identidade? Produz-se como efeitos a expulsão destas pessoas deste espaço, por se sentirem rejeitadas, desrespeitadas, discriminadas.

O não reconhecimento da identidade das travestis como uma identidade válida, mas como algo desnecessário, aponta para aquilo que talvez seja a maior barreira para que esse segmento consiga alcançar o exercício pleno de seus direitos no ambiente escolar. Se ser travesti é algo desnecessário, se não é algo sério ou se eu não reconheço essa identidade, então, não faz sentido pensar no uso do banheiro feminino, no nome social na chamada e em nenhuma reivindicação que venha nesse sentido. (Bortolini, 2008, p. 16).

Bortolini (2008) evidencia ainda o quanto os professores, por vezes, culpabilizam a vítima de transfobia em casos de violência na escola, quando conversam com estes alunos para saber quais atitudes levaram os demais alunos a agredi-los ou chamariam os pais do aluno agredido. Isso deixa claro o quanto a criminalização da transexualidade age nas escolas, podendo acontecer através de todos os membros que constituem uma escola.
Como compreendido pelo trabalho de Bento (2014), há um atraso na lei brasileira de forma a garantir os direitos das pessoas transexuais. Nossa lei, no tocante às instituições - não só a escola, mas também bancos, repartições públicas e outros espaços institucionais - promove o embaraço e uma hierarquização de poder da verdade psiquiátrica sob a identidade trans, apenas tendo o gênero com o qual se identifica plenamente reconhecido quando obtém um laudo psiquiátrico que permita a cirurgia de redesignação. Do contrário, em seus documentos e formas de tratamento serão considerados tal qual o sexo biológico, um desrespeito ao seu desejo e subjetividade.

Além deste tipo de violência, que torna o ambiente escolar um ambiente desagradável à pessoa transexual, é de conhecimento geral situações nas quais se fazem presentes a agressão física, o denominado bullying, violências sexuais por parte de outros estudantes do meio escolar, entre outras violações. Todo indivíduo que, de alguma forma, foge à heteronormatividade, não sendo necessária a comprovação de sua orientação sexual, bastando apenas a suspeita por "trejeitos" considerados como anormais e fora do padrão de seu gênero atribuído antes de nascer, terá um olhar diferenciado pelo meio social para si. O indivíduo sofrerá práticas perversas de agressão e tal quadro é agravado quando há a manifestação de caracteres transexuais, havendo ainda maior incidência de violência e preconceitos a estes (Cassal \& Bicalho, 2011).

\section{E a Escola?}

De acordo com os Parâmetros Curriculares Nacionais para o Ensino Fundamental (Brasil, 1997), a explicitação de pressupostos pedagógicos e conteúdos programáticos têm importância estratégica na implementação de políticas públicas de Educação no Brasil, no sentido de que possam potencializar processos de ensinoaprendizagem das formas mais diversas, além de acompanhá-los e avaliá-los. Tal potência refere-se às diretrizes de respeito às diferentes diversidades que compõem o cenário sociocultural brasileiro, 
no sentido de produzir contextos para o acesso aos conhecimentos socialmente produzidos, visando à constituição da cidadania.

Nesse sentido, além dos conteúdos disciplinares previstos e distribuídos por cada período, há a previsão de temas que devem perpassar todo o processo educativo, ao longo dos anos: os temas transversais. Tais temas constituem-se a partir de questões sociais urgentes e trazem a perspectiva do cotidiano: a necessidade de abordar temas que correspondam às questões do dia a dia dos estudantes brasileiros. A Lei Nacional de Diretrizes e Bases (Lei no 9.394, de 20 de dezembro de 1996), em seu artigo 27, inciso I, indica a necessidade da difusão de valores fundamentais ao interesse social e aos direitos e deveres dos cidadãos, indicativos da ordem democrática ${ }^{3}$. Assim, os temas transversais indicados para o Ministério da Educação são para o ensino fundamental no Brasil: Ética, Pluralidade Cultural, Meio Ambiente, Saúde, Orientação Sexual e Temas Locais (Brasil, 1998).

Mas, o que seriam esses temas transversais na prática? Como tratar de um assunto de forma transversalizada? Como é possível dar conta dos conteúdos previstos e de assuntos transversais, em contextos que muitas vezes não são propícios para a reflexão crítica? Nessa perspectiva, a partir de todos esses questionamentos, apresentamos a proposta de, ao longo deste manuscrito, esmiuçarmos algumas dessas questões, não necessariamente produzindo respostas, mas ampliando o campo de problemáticas, apresentando diferentes pontos de vista e traçando redes e novos planos comuns.

A partir do exposto, fica evidente que a escola é ainda, hegemonicamente, um ambiente hostil e que expulsa as pessoas trans, seja pela omissão no combate a violência ou pelo estabelecimento de práticas claramente discriminatórias, como impedir que pessoas trans utilizem o banheiro consonante com a sua identidade de gênero e/ou ao se recusar a chamar o aluno pelo nome social.

Ainda assim, propostas como do kit antihomofobia, de 2011, são vetados pela política Brasileira. Mesmo hoje não há devolutiva do MEC de novos projetos ou do destino do kit homofobia, projetado por uma equipe de cerca de 500 profissionais (Chagas, 2012). Mesmo que o projeto tenha sido vetado, a sua elaboração demonstra que há pessoas resistindo, para que essas discussões ocorram nas escolas. Há educadores, integrantes da sociedade civil, militantes dos movimentos sociais e políticos clamando por esclarecimento. Há retrocessos, mas também há resistência. Estes são os efeitos possíveis da criminalização: a estigmatização também produz visibilidade capaz de organizar formas de resistência e potências de diferenciação. E o profissional psicólogo, na escola, pode produzir interessantes análises, provocar diferentes coletivos, construir intervenções produtoras de vida. Ou, por outro lado, atuar como mais um "amolador de facas" (Baptista, 1999).

De acordo com Silva e Paveltchuk (2014):

Se há não muito tempo o debate sobre sexualidade na escola era restrito a questões biológicas e de saúde, hoje percebemos a necessidade de se incluir questões voltadas para a diversidade. Essa necessidade reflete questões sociais que emergem a partir da luta de diversos segmentos, passando a ampliar o conceito de sexualidade, incluindo diversas formas de expressão humana. Da mesma forma, a discussão sobre a construção sócio-histórica das identidades de gênero passa a habitar o espaço escolar, tornando-se disparadora de dúvidas e possibilidades de trabalho docente. Não se trata de dizer que somente agora a escola está permeada pela diversidade, e sim de que esse fator passa a ser objeto de análise do campo de estudo educacional. (p. 11)

Diante deste quadro, urge a necessidade da promoção de debates no meio escolar através dos mais variados dispositivos, como oficinas junto aos professores e alunos, trazendo o questionamento das verdades postas quanto à sexualidade e ao gênero. Esta pode ser uma tarefa para a Psicologia na escola, como uma disciplina no ensino médio. Que sejam discutidas as formas de estigmatização, os processos de criminalização e seus efeitos

${ }^{3}$ http://www.planalto.gov.br/ccivil_03/leis/L9394.htm 
na construção de uma normalidade forjada e adequada à ordem social.

É importante que o debate não seja silenciado na escola, local primordial para formação de indivíduos e seus valores. A escola, quando um meio que não promove a exclusão, é um grande auxiliar (embora não único) para que os indivíduos, que fizeram parte do corpo escolar um dia, promovam uma forma mais plural de pensar, não concebendo a transexualidade como doença e/ ou como um "erro" comportamental, auxiliando, portanto, na desconstrução de preconceitos.

Apenas através da compreensão e debate dos discursos criminalizantes que atravessam nossas existências poderemos construir novas normas e construções de subjetividades que agreguem e, verdadeiramente, respeitem os direitos que cada travesti e transexual deveria ter assegurado.

\section{Referências}

Arán, M. (2006). A Transexualidade e a gramática normativa do sistema sexogênero. Ágora Estudos em Teoria psicanalítica, 9(1), 49-63. doi: 10.1590/S151614982006000100004

Arán, M., Murta, D. \& Lionço, T. (2009). Transexualidade e saúde pública no Brasil. Ciência \& saúde coletiva, 14(4), 1141-1149. doi: 10.1590/S1413-81232009000400020

Baptista, L. A. (1999). A atriz, o Padre e a Psicanalista - os Amoladores de Facas. In Baptista, L. A. A Cidade dos Sábios: reflexões sobre a dinâmica social nas grandes cidades (pp. 45-49). São Paulo: Summus.

Baratta, A. (2013). Criminologia crítica e crítica do Direito Penal. Rio de Janeiro: Revan.

Bento, B. (2011) Na escola se aprende que se aprende que a diferença faz a diferença. Estudos Feministas, 19 (2), 548-559. Recuperado de http://www.scielo.br/pdf/ref/ v19n2/v19n2a16

Bento, B. (2014). Nome social para pessoas trans: Cidadania precária e gambiarra legal. Contemporânea, 4 (1), 165182. Recuperado de http://www.contemporanea.ufscar. br/index.php/contemporanea/article/view/197

Bicalho, P. P. G., Geraldini, J. R., Magalhaes, K. C. \& Cassal, L. B. (2012). Os direitos sexuais e o enfrentamento da violência sexual. Psicologia Clínica, 24 (1), 33-43. doi: 10.1590/S0103-56652012000100003

Bortolini, A. (2008). Diversidade sexual na escola. Rio de Janeiro: PróReitoria de Extensão/UFRJ.

Bortolini, A., Bicalho, P. P. G., Mostafa, M., Colbert, M., Polato, R. \& Pinheiro, T. F. (2014). Trabalhando Diversidade Sexual e de Gênero na Escola: Currículo e Prática Pedagógica. Rio de Janeiro: PróReitoria de Extensão/ UFRJ.

Brasil. Secretaria de Educação Fundamental. (1997). Parâmetros curriculares nacionais: apresentação dos temas transversais, ética. Brasília: MEC/SEF.

Brasil. Secretaria de Educação Fundamental. (1998). Parâmetros curriculares nacionais: terceiro e quarto ciclos do ensino fundamental: introdução aos parâmetros curriculares nacionais. Brasília: MEC/SEF.
Brasilpost. (2015). Policiais militares são presos após mentirem sobre o assassinato da travesti Laura Vermont em SP. Recuperado de http://www. brasilpost.com.br/2015/06/23/morte-travesti-lauravermont_n_7643948.html

Cassal, L. C. B. \& Bicalho, P. P. G. (2011). "Não importa ser ou não ser, importa parecer": Pistas sobre violência homofóbica e educação. In A. Bortolini (Org.). Diversidade Sexual e de Gênero na Escola: Educação, Cultura, Violência e Ética (pp. 78-93). Rio de Janeiro: PróReitoria de Extensão/UFRJ.

Cassal, L. C. B., Monteiro, A. G. \& Bicalho, P. P. G. (2011). Psicologia e o dispositivo da sexualidade: biopolítica, identidades e processos de criminalização. Psico, 42 (4), 465-473. Recuperado de http://revistaseletronicas. pucrs.br/ojs/index.php/revistapsico/article/ viewFile/8600/7451

Chagas, A. (2012). Um ano após veto, ABGLT quer resposta sobre kit anti-homofobia. Recuperado de https://noticias. terra.com.br/educacao/um-ano-apos-veto-abglt-querresposta-sobre-kit-anti-homofobia,f64a42ba7d2da31 OVgnCLD200000bbcceb0aRCRD.html

Cidade, M. L. R. \& Bicalho, P. P. G. (2016).“O nome é a primeira coisa!”: reflexões sobre a alteração do registro civil de pessoas trans* no estado do Rio de Janeiro. In F. Seffner, \& M. Caetano (Orgs.) Discurso, discursos e contra-discursos latino-americanos sobre a diversidade sexual e de gênero (pp. 895-905). Rio Grande: Ed.FURG.

Cruz, E. F. (2011). Banheiros, travestis, relações de gênero e diferenças no cotidiano da escola. Revista Psicologia Política, 11(21), 73-90. Recuperado de http://pepsic. bvsalud.org/scielo.php?script=sci_arttext\&pid=S1519549X2011000100007

Cunha, T. C. \& Bicalho, P. P. G. (2015). A Violência nas Escolas e a produção do medo como discurso de ordem. In M. A. K., Guindani, (Org.). Educação em Direitos Humanos: relatos de experiências no campo do ensino, pesquisa e extensão universitária (pp. 135-150). Rio de Janeiro: Montenegro. 
Dornelles, J. R. (1988). O que écrime. São Paulo: Brasiliense. Foucault, M. (1976/1993). História da sexualidade: a vontade de saber. Rio de Janeiro: Graal.

Jesus, J. G. (2010). Pessoas Transexuais Como Reconstrutoras de Suas Identidades: reflexões sobre o direito ao gênero. In Anais do Simpósio Gênero e Psicologia Social: diálogos interdisciplinares (p.80-89). Brasília, DF: Universidade de Brasília.

Organização da Nações Unidas (1948). A declaração universal dos direitos humanos. Recuperado de http://www.dudh. org.br/declaracao/

Organização Mundial da Saúde. (2010). Classificação Estatística Internacional de Doenças e Problemas Relacionados à Saúde - CID-10. Recuperado de http:// www.datasus.gov.br/cid10/v2008/cid10.html

Lapa, N. (2013). O preconceito contra transexuais no mercado de trabalho. Recuperado de http://www.cartacapital. com.br/blogs/feminismopraque/opreconceitocontratransexuaisnomercadodetrabalho2970.html

Silva, D. V. \& Paveltchuk, F. (2014). Olhares atentos: sobre a escola e a heteronormatividade. In P. P. G. Bicalho, T. C. Cunha, M. L. R. Cidade, \& A. Assunção-Matos (Orgs.). Gênero e Diversidade na Escola: práticas transversais, polifônicas, compartilhadas, inquietas. (pp. 50-63). Rio de Janeiro: UFRJ

Silva, M. R. C. G. \& Bicalho, P. P. G. (2014). Gênero e criminalização na experiência transexual. Revista do CFCH, ed.esp., 1-5. Recuperado de http://revista.cfch. ufrj.br/images/edicao-jic2013/silva-mariah.pdf

Siqueira, C. (2008). Protesto pede que transexual recupere guarda de criança. Recuperado de http://www.estadao. com.br/noticias/geral,protestopedequetransexualrecupereguardadecrianca, 105610 